\title{
TINGKAT PEMAHAMAN PERATURAN PERMAINAN SEPAKBOLA (LAW OF THE GAME) WASIT C-2 DAN C-1 ASPROV PSSI BENGKULU
}

\author{
Yarmani \\ Universitas Bengkulu \\ Yarmani62penjas@gmail.com \\ Dika Irwanto \\ Universitas Bengkulu \\ Sofino \\ Universitas Bengkulu
}

\begin{abstract}
ABSTRAK
Penelitian ini bertujuan untuk mengetahui tingkat pemahaman wasit terhadap peraturan permainan sepakbola. Penelitian ini merupakan penelitian deskriptif kualitatif. Metode yang digunakan dalam penelitian ini adalah metode survei. Instrumen yang digunakan adalah angket. Instrumen yang telah tersusun tersebut dikonsultasikan kepada ahli (expert judgment). Populasi dalam penelitian ini adalah wasit sepakbola C-2 dan C-1 Asprov PSSI Bengkulu dengan jumlah 25 orang. Teknik analisis data yang dilakukan adalah analisis deskriptif dengan persentase. Hasil penelitian menunjukkan bahwa tingkat pemahaman peraturan permainan sepakbola (Laws of The Game) wasit C-2 dan C-1 Asprov PSSI Bengkulu berada pada kategori sangat baik sebesar 92\% (23 orang), kategori baik sebesar $8 \%$ ( 2 orang), kategori cukup sebesar $0 \%$, kategori kurang $0 \%$,dan kategori sangat kurang $0 \%$. Dengan rincian lisensi yaitu sebanyak 6 orang lisensi C-1 dan 17 orang lisensi C-2 termasuk ke kategori sangat baik sedangkan 2 orang berlisensi C-2 termasuk ke kategori baik.
\end{abstract}

Kata Kunci: Tingkat Pemahaman, Peraturan Permainan Sepakbola, Asprov PSSI Bengkulu.

\begin{abstract}
This study aims to determine the level of referees' understanding of the rules of the game of football. This research is a qualitative descriptive study. The method used in this study is a survey method. The instrument used was a questionnaire. The instruments that have been arranged are consulted to the expert (expert judgment). The population in this study were C-2 and C-1 Asprov PSSI Bengkulu soccer referees with a total of 25 people. The data analysis technique used is descriptive analysis with a percentage. The results showed that the level of understanding of soccer regulations (Laws of the Game) C-2 and C-1 Asprov PSSI Bengkulu referees were in the very good category at $92 \%$ ( 23 people), good categories at $8 \%$ ( 2 people), enough categories at $0 \%$, less categories at $0 \%$, and very less categories at $0 \%$. With the details of the license, there are $6 \mathrm{C}-1$ licenses and 17 C-2 licenses included in the very good category while 2 C-2 licensed people are included in the good category.
\end{abstract}


Keywords: Understanding Level, Football Game Rules, Asprov PSSI Bengkulu.

\section{PENDAHULUAN}

Wasit merupakan pemimpin di lapangan yang wewenangnya mutlak dalam menegakkan peraturan permainan pada pertandingan dimana ditugaskan (Laws Of The Game, 2014). Dalam satu pertandingan sepakbola dipimpin oleh seorang wasit, asisten wasit 1 , asisten wasit 2 dan wasit cadangan. Karenanya wasit pertandingan dilindungi sepenuhnya oleh badan sepakbola dunia yaitu Federation Internationale de Football Association (FIFA). Wasit di lapangan juga punya peran menentukan pada kualitas sebuah pertandingan, serta kenyamanan suatu pertandingan untuk dinikmati. Kesalahan pengambilan keputusan pada saat memimpin pertandingan oleh seorang wasit maka akan menodai pertandingan tersebut. Bukan hanya menodai pertandingan terkadang di dalam suatu pertandingan apabila wasit melakukan kesalahan akan terjadi beberapa reaksi dari berbagai kalangan baik pemain, pelatih, official maupun supporter. Kebanyakan reaksi yang ditunjukkan dari kalangan tersebut yaitu reaksi secara emosional. Reaksi emosional tersebut akibat dari adanya suatu ketegangan atau stress (I Ketut Iwan Swadesi,2011).Reaksi emosional yang ditimbulkan oleh pemain, pelatih, official maupun supporterdikarenakan kurangnya pemahaman peraturan yang diketahui oleh mereka ditambah lagi kurangnya rasa menghormati terhadap kepemimpinan wasit yang bertugas menimbulkan persepsi yang berbeda terhadap keputusan wasit sehingga mengakibatkan reaksi emosional di lapangan.

Dari hasil observasi yang telah peneliti lakukan, kompetisi sepak bola di Asosiasi Provinsi (Asprov) Persatuan Sepakbola Seluruh Indonesia (PSSI)
Bengkulu dalam rentang tahun 2015-2017 terakhir hanya mengadakan kompetisi Liga Nusantara,Liga 3 Regional Bengkulu yang di ikuti oleh beberapa klub saja, tapi pertengahan tahun 2018 mulai di adakan kembali kompetisi tingkat junior seperti Menpora Cup, Piala Soeratin, Piala Danone, Pertiwi Cup untuk para wanita.Kondisi kurangnya kompetisi sepakbola di rentang tahun 2015-2017 di Asosiasi Provinsi (Asprov) Persatuan Sepakbola Seluruh Indonesia (PSSI) Bengkulu ini dampak dari pembekuan persatuan sepakbola seluruh Indonesia (PSSI) oleh Mentri Pemuda dan Olahraga (Menpora) 4 tahun lalu. Semoga dengan dicabutnya pembekuan Persatuan Sepakbola Seluruh Indonesia (PSSI) oleh mentri Pemuda dan Olahraga (Menpora) pada tahun 2016 akan mengembalikan gairah persepakbolaan di Bengkulu khususnya dan di seluruh Indonesia pada umumnya.Berdasarkan uraian di atas, maka peneliti ingin meneliti Tingkat Pemahaman Peraturan Permainan Sepakbola (Laws of TheGame) wasit C-2 dan C-1 Asprov PSSI Bengkulu. Pada penelitian kali ini peneliti hanya menggunakan subjek wasit yang mempunyai Certificate 2 dan Certificate 1 karena dengan berbagai pertimbangan salah satunya, menurut peniliti wasit yang mempunyai Certicate 2 dan Certificate 1 lebih mempunyai pengalaman dalam hal memimpin pertandingan yang jenjang atau level bertugasnya lebih tinggi daripada wasit yang mempunyai Certifcate 3.Dari penelitian ini akan terungkap seberapa tinggi pemahaman wasit terhadap peraturan permainan sepakbola (Laws of The Game). Peneliti merasa khawatir dan peduli terhadap kemajuan kualitas wasit sepakbola, maka peneliti mengangkat permasalahan tersebut dalam penyusunan 
skripsi yang berjudul "Tingkat Pemahaman Peraturan Permainan Sepakbola (Laws Of The Game) Wasit C-2 dan C-1 Asprov PSSI Bengkulu".

\section{METODE}

Penelitian merupakan kegiatan sistematik yang dimaksudkan untuk menambah pengetahuan baru atas pengetahuan yang sudah ada. Dengan adanya cara yang dapat dikomunikasikan dan dapat dinilai kembali. Sebelum melakukan penelitian dibutuhkan terlebih dahulu desain penelitian agar nantinya penelitian dapat terarah dan berjalan secara sistematis. Desain penelitian ini adalah penelitian deskriptif kualitatif dengan metode survey yang menggunakan angket. Menurut Suharsimi Arikunto (2006:78) "penelitian deskriptif merupakan penelitian non hipotesis tetapi hanya menggambarkan seperti apa adanya tentang suatu keadaan". Dalam penelitian ini peneliti bermaksud mencari fakta, menafsirkan fenomena yang terjadi dan selanjutnya menjelaskan secara deskriptif dengan menggunakan kata-kata atas fakta yang bersangkutan seperti apa adanya. Penelitian ini bermaksud mengetahui seberapa baik tingkat pemahaman peraturan permainan sepakbola (Laws of The Game) wasit C-2 dan C-1 Asprov PSSI Bengkulu dan berusaha mencari informasi, gambaran secara teratur, ringkas dan jelas mengenai suatu gejala peristiwa sehingga dapat ditarik makna tertentu.

\section{HASIL DAN PEMBAHASAN HASIL}

Berdasarkan hasil yang di dapat menunjukkan bahwa dari keseluruhan subjek penelitian yang berjumlah 25 orang, sebanyak 2 orang (8\%) subjek penelitian lainnya memiliki pemahaman yang baik pada pemahaman peraturan permainan sepakbola, sedangkan sebanyak 23 orang (92\%) sujek penelitian lainnya memiliki pemahaman yang sangat baik pada pemahaman peraturan permainan sepakbola, dimana wasit yang berlisensi C1 dengan jumlah 6 orang dan wasit C-2 dengan jumlah 17 orang masuk ke kategori sangat baik sedangkan 2 orang wasit yang berlisensi C-2 masuk ke kategori baik. Berdasarkan hasil analisis data tersebut dapat disimpulkan bahwa tingkat pemahaman peraturan permainan sepakbola (Laws of The Game) wasit C-2 dan C-1 Asprov PSSI Bengkulu termasuk sangat baik.

\section{PEMBAHASAN}

Tujuan dari penelitian ini adalah untuk mengetahui tingkat pemahaman peraturan permainan sepakbola (Laws of The Game) wasit C-2 dan C-1 Asprov PSSI Bengkulu. Hasil analisis deskriptif menunjukkan bahwa tingkat pemahaman peraturan permainan sepakbola (Laws of The Game) wasit C-2 dan C-1 Asprov PSSI Bengkulu adalah sangat baik. Hal ini terlihat dari hasil analisis data yang menunjukkan bahwa mayoritas subjek penelitian yaitu sebanyak 23 orang (92\%) memiliki tingkat pemahaman yang sangat baik terhadap peraturan permainan sepakbola, sebanyak 2 orang (8\%) memiliki tingkat pemahaman kategori baik terhadap peraturan permainan sepakbola, sebanyak $0 \%$ kategori cukup, sebanyak $0 \%$ kategori kurang, dan sebanyak $0 \%$ kategori sangat kurang, dimana wasit berlisensi C-1 dengan jumlah 6 orang dan wasit C-2 dengan jumlah 17 orang yang termasuk ke kategori sangat baik sedangkan wasit berlisensi C-2 dengan jumlah 2 orang termasuk ke kategori baik.

Untuk 23 orang (92\%) memiliki tingkat pemahaman yang sangat baik terhadap peraturan permainan sepakbola karena masih aktif dalam menjalani profesi sebagai wasit dan sering berdiskusi antar anggota wasit mengenai peraturan permainan sepakbola. Diskusi biasanya 
dilakukan pada waktu pertemuan wasit dan pengawas pertandingan.

\section{PENUTUP}

\section{SIMPULAN DAN SARAN}

Berdasarkan hasil analisis pada pembahasan, dapat disimpulkan bahwa secara keseluruhan tingkat pemahaman peraturan permainan sepakbola (Laws of The Game) wasit C-2 dan C-1 Asprov PSSI Bengkulu adalah sangat baik. Sebanyak 23 orang (92\%) memiliki tingkat pemahaman yang sangat baik terhadap peraturan permainan sepakbola, sedangkan sebanyak 2 orang $(8 \%)$ memiliki tingkat pemahaman dalam kategori baik terhadap peraturan permainan sepakbola, sebanyak $0 \%$ kategori cukup,sebanyak $0 \%$ kategori kurang, dan sebanyak $0 \%$ kategori sangat kurang dengan rincian lisensi yaitu sebanyak 6 orang lisensi $\mathrm{C}-1$ dan 17 orang lisensi C-2 termasuk ke kategori sangat baik sedangkan 2 orang berlisensi C-2 termasuk ke kategori baik.Setelah melakukan penelitian tentang "Tingkat Pemahaman Peraturan Permainan Sepakbola (Laws Of The Game) Wasit C2dan C-1 Asprov PSSI Bengkulu", maka penulis memberikan saran-saran sebagai berikut:

1. Bagi wasit sepakbola C-2 dan C-1 Asprov PSSI Bengkulu untuk tetap mengembangkan kemampuannya dalam perwasitan dengan cara mempelajari lebih baik mengenai peraturan permainan sepakbola (Laws OfThe Game) dan meningkatkan kemampuan memimpin pertandinganmelalui latihan-latihan secara praktek di lapangan.

2. Bagiwasit yang sudah lama tidakbertugas di harapkantetapmenjagakondisifisikdan mengikutiperubahan-perubahan yang terdapatpadaperaturanpermainansep ak

bola karenasetiaptahunnyadiperbaharuiole hFederationInternationale de Football Association (FIFA) agar nantinyaapabiladitugaskanselalusiap.

3. Bagi komisi wasit khususnya Asprov PSSI Bengkulu agar lebih memanajemen dan memberikan pelatian-pelatihan tambahan terhadap wasit-wasit Asprov PSSI Bengkulu.

\section{DAFTAR PUSTAKA}

Agusta, W. 2012. Sepak Bola. Rajagrafindo Persada. Jakarta.

Andika dkk. 2012. Pengaruh Model Permainan Terhadap Hasil Passing Sepak

Bola Pada Kelas VIII A SMP N 4 Sambas Tahun Ajaran 2011/2012. Jurnal. UNTAN. Pontianak

Arikunto, Suharsimi. 2006. Prosedur Penelitian Suatu Pendekatan Praktik.Jakarta: PT. Kineka Cipta.

Azidman, Leo.2017. Profil Kondisi Fisik Pemain Sepak Bola SMA NEGERI 1 Kaur. Jurnal KINESTETIK. Vol 1, hal 2.

Dewa, R.T. 2015. Penyusunan Norma Kebugaran Aerobik Untuk WasitTaekwondo Daerah Istimewa Yogyakarta. Skripsi. Universitas Negeri Yogyakarta

Fatoni. 2013. Survei Tingkat Pemahaman Pemain Sepakbola Usia 13-15 Tahun Terhadap Peraturan Sepakbola (Laws Of The Game) 2010/2011 Di SSB SEKabupaten Temanggung Tahun 2013. Skripsi. Semarang: FIK UNNES

Nugraha, A.C. 2012. Mahir Sepakbola. Nuansa Cendekia. Bandung.

Pujianto, D , Insanistyo, B. (2017) Dasardasar Penelitian Pendidikan Jasmani. Bengkulu : FKIP Universitas Bengkulu.

Sucipto, dkk. 2000. Sepakbola. Departemen Pendidikan Dan Kebudayaan.Jakarta. 
